\title{
Lope Cilleruelo, una biografía para la historia de la Orden Agustiniana
}

Razón de este artículo

Una vida puede verse reproducida en unas páginas como si se la pasase objetiva y documentalmente por delante de un espejo. Esto seria una biografía clásica, al antiguo modo. Pero puede añadírsele un contorno espacio-temporal, y unas circunstancias y actividades: ambiente, colorido, anécdotas, personajes subalternos y concordantes, movidos en el guiñol de una trama, entre pícara y severa, que se adhiere a los datos históricos y que nos reflejan así, mucho mejor, el vivir de su protagonista.

Puede contemplarse, también, esa vida "desde dentro" del alma misma del personaje, en un esfuerzo intuitivo y evocador; con 10 que tendremos una auténtica biografía.

En estàs páginas, que son solamente el esbozo de una biografía, quiero hacer un poco lo que acabo de apuntar; consciente de que el personaje vive todavía entre nosotros y corriendo el riesgo de que algunas anécdotas y acontecimientos del biografiado serán motivo, si no de polémica, sí de diversos juicios y enjuiciámientos. Lo cual es del todo correcto y entra dentro del modo de ser de los hombres.

Por lo que al personaje principal se refiere, estoy convencido de que no querría se publicaran algunas cosas que aquí han de salir por fuerza. La naturalidad y humildad son propias y condición de los hombres sabios y desinteresados. Otras muchas cosas quedarán por decir; porque, de momento, es así mejor. Conozco al P. Lope Cilleruelo y sé que huye de elogios. Pero creo que, aunque le disguste, es de toda justicia dejar aquí estampada su vida, siquiera para oque, conociendo más a fondo su buen hacer y quehacer a su paso por la tierra, tengamos una imagen más clara del hombre sincero $\mathrm{y}$ bueno, del religioso cabal, del sacerdote comprensivo y humano, del profesor genial, del escritor, del "camarada"; del hermano y amigo, de nuestro discutido y amado P. Lope Cilleruelo. 
Por otra parte, quiero hacer constar, ya desde el principio, mi profundo agradecimiento al P. Dictinio Rodriguez Bravo y a Aquilina Cilleruelo; ya que estas dos personas me han suministrado datos y anécdotas tan de primera mano que constituyen, sin duda, lo mejor de este trabajo, escrito con veneración y cariño por cuanto este hombre hizo por los de nuestra generación y que aún quedamos para ser juzgados y enjuiciados como lo es él.

El P. Lope Cilleruelo ha estado siempre a la vista de todos y es una de las figuras religiosas de la Provincia Agustiniana de Filipinas, y aun creo que de toda la Orden, que no necesita presentación, ni de ponderaciones. Lo que ha sido, representa y vale su obra docente y literaria - sigo el pensamiento del P. Dictinio-, su dimensión religiosa y humana no constituyen ningún misterio. No se trata de un espíritu introvertido, sino de un personaje abierto, siempre propicio al diálogo y a la comunicación. El P. Lope es un hombre en quien toda su vida ha estado marcada y presidida por la laboriosidad, el optimismo, el talante deportivo en su más noble acepción y el encauzamiento de sus energias vitales por el doble cauce del profesorado y de la pluma que configuran el auténtico ideal de su vocación sacerdotal y agustiniana.

Mérito suyo es y no pequeño el haber sabido hablar y escuchar. $\mathrm{Y}$ vivir a su estilo, sin entorpecer nunca la marcha de los demás; antes, animando a muchos - como hemos de ver en este trabajo-, y alegrándose siempre con el triunfo de los demás. El P. Lope ha sabido muy bien identificar la comprensión con la caridad: aplacando muchas tensiones y arreglando muchas cosas con el sutil almibar de una salida ingeniosa, de una historieta intrascendente, de un alarde jocoso que relajaban las cargas pasionales y hacian florecer, de inmediato, la sonrisa sedante y conciliadora.

El tono, a veces, festivo del relato y del comentario que aparecerá en estas páginas tiene su importancia en la vida del P. Lope. Aquí habrá que saber leer entre líneas y ahondar por debajo de la anécdota para apreciar en todo su valor y significado la lección que nos ha dado a todos de sinceridad y de caridad nuestro biografiado.

\section{De la tierra de "El Empecinado"}

Lope va a nacer un 25 de septiembre de 1908 en la villa de Roa de Duero, la antigua "Ronda" o "Rodacis" de los romanos. La villa histórica que se mira en el "padre" Duero desde la barbacana de su Espolón y desde el que se contempla un paisaje -el de su vega y pueblos de alrededor-que, en la palabra y pluma de don José Ma. 
Pemán, bien vale por un libro de rezos. Roa, famosa en tiempos de doña Urraca, la hija de Alfonso VI y que defendió a esta princesa contra su esposo, Alfonso I de Aragón. Roa, entregada en lote a doña Blanca de Navarra, con motivo del casamiento con Enrique IV de Castilla. Roa, celebrada por su magnifica colegiata de un gótico tarcio, y que albergó un día a un grupo de canónigos regulares de San Agustín. Roa, con su palacio real, propiedad más tarde de los Velasco, duques de Alburquerque, encabezados por don Beltrán de la Cueva, cuya inscripción figura en el escudo de la villa. Precisamente, en este palacio moriria en el año 1517 el Cardenal Cisneros, cuando iba camino de Valladolid y al encuentro del joven emperador Carlos que entraba por primera vez en Castilla. Roa, famosa en la guerra de la Independencia, con sus guerrilleros "El Cura Merino" y "El Empecinado", este último ajusticiado en la villa el año 1825. La villa de Roa, saqueada y quemada por Balmaseda, general de los carlistas, el año 1840, de retirada hacia Estella, tras el "Convenio de Vergara" entre Maroto y El Duque de la Victoria.

Cuando nace el P. Lope, por la Ribera del Duero andan los conservadores y los liberales ganándose los votos de sus gentes noblotas y rudas, pendencieras y - según dicen- de armas tomar. Cuando lleguen los días del más celebrado de sus caciques, don Diego Arias de Miranda, el P. Lope es un chaval espabilado y listo que va a decir pronto adiós a su tierra para marchar a otra ribera, esta vez del río Esla y en la villa leonesa de Valencia de Don Juan.

La casa en que nace Lope es humilde. Una parra da sombra a la fachada de piedra durante el verano y solaz a sus dueños que, sentados en los poyos que existen a un lado y otro de la puerta de entrada, descansan de las duras faenas del campo, y al regreso de "acollar" la cepa o de regar la huerta en plena sazón.

El padre de Lope, el señor Víctor, era uno de esos hombres que caen simpáticos a los vecinos y compadres por su campechanía, gracia natural y honradez en el cumplimiento de sus deberes profesionales. El señor Víctor se hará famoso entre los vecinos de Roa y entre los frailes agustinos. Lo hemos de ver enseguida.

La madre era una brava, dulcificada mujer aldeana, en torno a la cual trabajaban a ritmo las horas, como si martillearan, para sumarse al afán de aquella esposa buena y madre de tres hijos, el primogénito de todos Lope.

Ya hemos dicho que, al tiempo de nacer Lope, España vivía la política del primer ministro de la monarquía, don Antonio Maura, $\mathrm{y}$ en el caciquismo provinciano sobresalía don Diego Arias de Miranda, cacique mayor de Aranda de Duero, amo, "padrecito" y pro- 
tector de los labradores de la zona, a los que prometia siempre un camino vecinal o una simple acequia de regadio en visperas de elecciones para diputados del Congreso.

Cuando niño, de la mano del señor Víctor, que por su cargo de policia municipal encontraba muchos ratos libres, Lope aprendió muy pronto a leer y escribir y hacer cuentas. Su hermana nos ha' dicho que le encantaban los libros. También de muy corta edad comenzó a ir a la escuela. $Y$ precisamente por eso, porque era muy pequeño, "no le daban las letras", en expresión de estos buenos castellanos; es decir, que no se preocupaban ni poco ni mucho de él. Pero Lope, que a los tres años "se sabía de memoria la cartilla", tenía que darse a conocer. Fue aquel día en que el señor Víctor preguntó a la maestra - doña Tomasa de nombre - por su hijo. Aquella mujer, no dando demasiado crédito a lo que el fornido ribereño Cecía de su pequeño, tomó a Lope por su cuenta y le preguntó las primeras letras. Imaginese el lector el asombro de la maestra cuando comprobó que "todo era verdad, y aún se había quedado corto su progenitor".

Cuando terminaba el curso en las Escuelas Municipales de Roa se organizaban sus pequeños festivales. Lope no podía faltar. $Y$ nos cuentan que el primer año que intervino, como era pequeño de estatura, tuvieron que subirlo a una silla y desde ella pronunció "sú discursito tan requetebién", que, aparte los aplausos merecidos y los besos de la señora maestra, le dieron un libro de premio, titulado Viaje Infantil.

El "discurso" del pequeño Lope hizo época; y en cuanto al lịbro, se lo sabía casi de memoria, y años adelante, el señor Víctor se 10 hizo aprender a sus nietos, que bien lo recuerdan todavía. El contenido trataba de un niño que iba de viaje con su padre, señor y dueño de tres mulas. Lope no lo dejaba ni de día ni de noche... "Ría, ría, coronela.. Ría, ría, comandanta.. Ría, ría, generala..." Vamos, que les volvía locos a todos, pues en cuanto el sol le guiñaba con su primer rayo a la ventana de su dormitorio, Lope "bajaba por el libro, cogía un cacho de pan y se estaba horas en la cama estudiando por él".

Había finales de curso en que los niños se atrevían con su pequeño teatro. $Y$ el hijo del señor Víctor siempre se llevaba un premio; sobre todo, cuando salía haciendo de criadillo, o paje de un gran señor, que era una gloria verlo.

Hijo de la Ribera y del campo, Lope ayudaba en las faenas de recolección y de riego de la huerta. Pero su verdadera afición eran 
los libros. Alguien nos ha recordado que "siempre muy humilde, euando llegaban los exámenes, le decía a su padre que no se sabia la lección". $Y$ el señor Victor, comprensivo y en el fondo orgulloso, le mandaba desde el campo a casa para que estudiara cuanto quisiera.

Pero ya en aquella corta edad dejaba entrever otras de las facetas que le acompañarán toda su vida: Lope era un gran despistado. La misma persona que me ha suministrado los datos de su infancia nos dice que una vez le dejó su padre regando en la vega. $Y$ como el muchacho se retrasara, fue a buscarle su madre. Cuando ésta llegó a la finca, le preguntó qué era lo que estaba haciendo. Y Lope contestó sencillamente que estaba esperando a que llegase el agua al surco; sin advertir que el agua se estaba marchando por otro sitio, fuera de la huerta propiedad de los Cilleruelo-García. Claro que, como dice nuestra "corresponsal", a esa edad, qué se iba a esperar y pedir de Lope...

Lope, además de regar la huerta, cuidaba por el mes de junio el hermoso habar. $Y$ su hermana le llevaba la comida. Cuando en las noches, luego, de verano su padre se quedaba a dormir en el corte de la siega, Lope, a lomos de un burro cachazudo, le llevaba la cena. Se hacía el valiente; pero a medio camino, y teniendo que atravesar por entre árboles y recodos, sentia de pronto miedo y se ponia a cantar una copla que había aprendido de los mozos de Roa. La copla rezaba así:

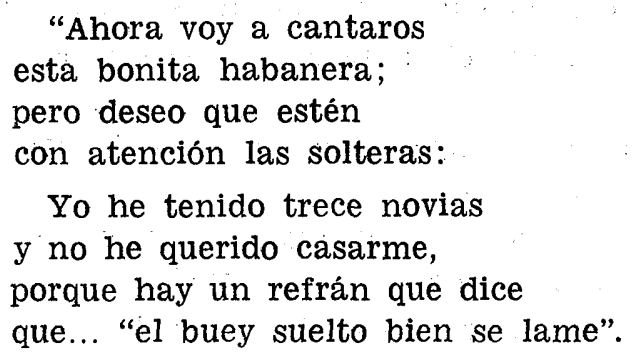

$Y$ de este modo, llegaba cantando su copla a la finca de "La Ambuena". Su padre, que estaba orgulloso de su primogénito, le preparó enseguida una cama de mies reseca y recién cortada, quedando roque con su canción entre los labios y ya del todo tranquilo.

Lo peor fue que, a media noche, se levantó una tormenta y hubo que llevarlo a una cabaña, que cerca había, donde siguió su sueño hasta el amanecer.

Lope, siendo todavía niño, denotaba ya la inquietud, la agudeza de ingenio y cierto espiritu independiente, que serán una cons- 
tante de su vida. Un día - nos cuentan-se escapó de casa; y costó mucho encontrarle porque se habia ido de "zagalejo" al cuidado de un rebaño de ovejas, metiéndose con ellas en el aprisco. Hasta que el pastor se dio cuenta y lo devolvió a sus padres.

Lope era un chico travieso y lo que se dice "un trasto". Cuando ingrese en la Apostólica de Valencia de Don Juan, llevará ya las marcas y cicatrices de sus caídas, y las señales de los puntos que le dieron; con más dolor, quizá, en los suyos que en él, pues era fuerte y duro, como las encinas y carrascales de su pueblo, de la otra parte que no es la vega.

\section{En Valencia de Don Juan.}

Y marchó a Valencia de Don Juan, muy joven todavía. Llegó a la antigua ciudad de Coyanza en el otoño de 1920. Contaba, pues, los 12 años de su edad. Curioso y yo diría, mejor, observador, montó en el tren de la Línea de Ariza, camino de Valladolid, y fue todo el tiempo asomado a la ventanilla, hasta el punto de que se le pusieron los ojos malos, no pudiendo estudiar en una buena temporada. Pero luego le sobrarian horas para ponerse al corriente de sus compañeros y sacar las mejores notas del curso.

Al llegar a la Apostólica, acompañado de su pađre, el religioso que lo recibió, P. Juan Manuel López, dijo al señor Victor:

- Este muchacho está delgado. ¿Acaso ha estado enfermo?

- Ca, no señor. Respondió el padre de la criatura. Está delgado de lo listo que es.

-No diga eso delante del muchacho - replicó el buen fraile agustino-; porque igual se lo cree.

-Este no se lo cree -contestó el ingenioso ribereño-, lo digo yo porque es verdad. $\mathrm{Y}$ si no, haga usted la prueba.

$\mathrm{Y}$ mientras el señor Víctor entregaba el hatillo de ropa y la exigua cantidad de dinero que entonces exigían para un caso de emergencia, el P. Juan Manuel le propuso una lección variada por mera curiosidad. Al poco tiempo volvieron junto al muchacho.

-Bien, pequeño, ¿ya te lo sabes?

-Sí, señor; respondió Lope todo seguro.

$\mathrm{Y}$ era verdad. En aquel momento pasó por allí uno de los postulantes con fama de listo y el P. Juan Manuel, dirigiéndose a él, le dijo:

- Oye, este chaval te va a ganar a ti y a todos. Ya lo verás. 
De casta le venía al galgo. Porque se cuenta -y es verdadque, faltándole al nuevo postulante una blusa y un cepillo para completar el equipo, salieron padre e hijo a comprar aquellos menesteres a la villa. $Y$ como volvieran con una sola cosa de las dos que pedía el $P$. Juan Manuel, éste reclamó cierta cantidad de dinero. Entonces el señor Víctor, muy serio y muy convencido, le dijo:

-Mire usted, yo ya no tengo más; pero le dejo una alhaja.

Tal vez a Lope no le hizo ninguna gracia aquella salida de su padre; pues bien se sabía él que más de un "chungón" le iba a llamar así. Pero el señor Víctor era como era y no tenía remedio.

Es el P. Dictinio quien completa este capítulo interesante de la vida de nuestro genial agustino. Oigámosle. "En septiembre de 1920 recalamos simultáneamente Lope y yo -nos dice- en Valencia de Don Juan con la sesera en blanco y el alma impoluta y abierta. Era nuestro patrimonio familiar engarzado en aire pueblerino, mitad tímido y mitad despierto, como si desde el agro castellano nos asomáramos a las Américas o al mar del Norte. Escoltados por nuestros respectivos progenitores comparecimos ante el P. Juan Manuel López, Rector del Colegio, que nos acogió con protocolo solemne y paternalista. Cayeron sobre su mesa unos papeles mugrientos y rugosos que acreditaban nuestra hombría de bien, la limpieza de nuestra sangre y el pálpito tembloroso de nuestra incipiente vocación religiosa. Hasta aquí discurrió la audiencia por los moldes de la más exquisita cordialidad".

Y a continuación nos cuenta la anécdota arriba descrita, con algunas pequeñas variantes a como yo la he conocido de labios de Aquilina Cilleruelo. Lo que no nos dice la hermana es que el señor Víctor se obstinó en su rotunda decisión diciendo:

-O me acepta a Lope sin más, o regresa conmigo al pueblo. Eso sí, le pesará toda la vida el haber desechado un talento.

$\mathrm{Y}$ a esto es a lo que el inteligente y bondadoso P. Dictinio llama "el carisma profético de D. Víctor Cilleruelo".

Pasaron los años de la Apostólica estudiando Humanidades; con aquellos métodos y aquellos profesores y aquellos hombres "de antes de la guerra": con sus virtudes, su entusiasmo, su vocación a toda prueba... Con sus fallos, sus imperfecciones, su vida..., tal y como tantas veces se la hemos oído contar al P. Lope, cuando era nuestro Maestro de Novicios o de Coristas, como antes se decía. Pero aquellos hombres - así y todo- eran formidables. Nuestro biografiado permaneció tres años en Valencia de Don Juan, siendo quizás el único colegial que, sin cuenta corriente, con mucho rostro y 
el respaldo de su padre, se enfrentó al futuro con la responsabilidad a cuestas de quien, al menos según el señor Víctor, habia nacido para ser genio.

\section{En el Noviciado en Valladolid}

Cuando Lope llega a Valladolid, le ha precedido en el viaje y destino el mismo P. Juan Manuel López que lo recibiera, siendo entonces su rector, en Valencia de Don Juan. Más cerca de su pueblo natal, con línea directa de ferrocarril y buenas comunicaciones para lo que entonces se exigia, la familia decidió venir a ver al futuro agustino que, al parecer, estaba contento.

Al P. Juan Manuel le faltó tiempo para bajar a la portería del convento y saludar de nuevo al señor Victor. Le recordó entonces la anécdota coyantina con estas sencillas palabras que a mi me suenan hoy un poco a profecía:

-De verdad, señor víctor, que nos dejó usted una alhaja.

Pero nuestro ribereño - mitad funcionario municipal, mitad campesino, no se las debia tener todas consigo. $\mathrm{Y}$ para probar a su hijo le dijo en tono muy solemne:

- Mira, Lope, vente con nosotros a casa, que nos haces mucha falta, y tu hermana Aquilina tiene que trabajar en el campo más de lo que puede como mujer.

A lo que Lope contestó, también sin titubeos:

-No, padre; que acá se está muy bien y yo estoy contento.

Lope se habia convertido en un guapo mozo, de bella estampa y ágil figura. Conservamos fotografías de entonces para quien lo quiera comprobar. Era el hermano mayor y hacía falta en casa. Pero sus padres no quisieron esclavizarlo al campo y lo entregaron generosamente a la Iglesia y a la Orden Agustiniana.

Contentos podían estar, igualmente, los PP. Juan Monedero y Graciano Zumel de aquel día en que fueron a la era del pueblo y hablaron con los padres del pequeño Lope, tratando de convencer a la madre, sobre todo, pues ésta no quería que su hijo fuera fraile por la sencilla razón de que un hermano suyo, el P. Silvestre Garcia, había marchado años atrás a China y no supieron más de él, a no ser que murió en aquel lejano país.

Más adelante se cambiaron las tornas. Cuando Fray Lope sea ya profeso de la Orden de San Agustín, la madre se mostrará orgullosa de su hijo, mientras tratará de hacer partícipe de su gozo a su 
marido que, un poco celosillo y como enfadado consigo mismo, solia repetir estas expresiones:

- Me parece que ya no soy su padre; pues él dice que lo es San Agustin.

El Noviciado es un año que se recuerda por todos. Año de prueba, decian nuestros antepasados. El año más feliz de mi vida religiosa, hemos oído decir a alguno. Cuando el P. Lope sea maestro de novicios procurará que sus pupilos lo pasen alegres, rompiendo viejos moldes de rigor, en medio de una vida seria, entregada a la oraeión y al estudio de la Regla y Constituciones. Los novicios de aquellos años no olvidarán nunca "las clases espirituales" del P. Lope Cilleruelo. Como tampoco podrán olvidar aquel romperse el esternón de risa franca y joven cuando, después del partido de baloncesto, agarraba el balón y contaba un chiste que siempre atribuía a su "amigo Manolo", o a algún viejo camarada de la guerra.

El noviciado de Lope transcurrió tranquilo desde octubre de 1923 al mismo mes de 1924. Profesó de votos temporales el día 1 del mes citado. Con sus 16 años cabales, era un adolescente de mente limpia, corazón ardiente, porte optimista, ingenuo y temperamental, juguetón y dócil, abierto y servicial con todos.

Puestos a recordar alguna anécdota de su noviciado, el P. Dictinio nos refiere que entre los oficios pintorescos que desempeñaban los novicios por riguroso turno estaba el de hojista. Consistia en pasar a tiempo las hojas del cantoral en las partes cantadas del ofcio o de la misa. Cuando Lope entraba en funciones, su actuación resultaba regocijante para los compañeros y preocupante para el P. Maestro: el que Lope volviera la hoja a su debido tiempo, sin que alguien le apuntara, era pura casualidad.

Otro oficio del hojista consistía en apagar las velas del altar al terminar las visperas. En ocasiones, la fantasia de Lope divagaba por otros espacios y había de intervenir algún vecino, el cual mediante un pisotón o tirándole de la capucha, le impelía a catapultarse hacia las velas, portador del soplo letal.

Alguna vez ocurría que, por vivir con la preocupación obsesiva de llegar a tiempo, apenas iniciadas las vísperas, le parecía escuchar un siseo y se lanzaba como un rayo, decidido, hacia las velas, que no podían aguantar la agresión ventosa de Lope, mientras el buen P. Blas Barrios, Maestro de novicios, vociferaba entre molesto y sorprendido:

$\because-$ Parece tonto. Encienda de nuevo las velas, hasta que termine el rezo. 
Pero el P. Blas sabía mucho de la buena voluntad de aquel novicio y de sus atolondramientos, nacidos del afán de acertar.

Lope y sus compañeros, al tiempo de franquear la puerta del noviciado habian entregado sus elementales enseres y ropas, recibiendo a cambio una túnica habituada a picar en otras espaldas, unos pantalones de serie, unos zapatos holgados y un hábito experto en cubrir vocaciones a toda prueba.

El invierno vallisoletano, de nieblas cerradas, largo y duro, lo soportaban los novicios a cuerpo limpio. Los sacerdotes y profesos recibian, en fecha determinada, un airoso y pesado manteo. Los novicios estaban en el año de prueba. $Y$ en la intimidad de su cuarto buscaban cobijo y calor al abrigo de una vieja manta. $Y$ aquí la anécdota, propia de nuestro despistado Lope: Fuera por informes mal interpretados, o por razones arcanas, un buen día al escuchar el requerimiento de la campana, se aseó precipitadamente, se colocó sobre sus espaldas la manta camera al estilo arriero y apareció en el coro escoltado por el regocijo delirante de sus connovicios y el pasmo desorbitado del P. Maestro.

Este era Fray Lope de novicio y tales despistes tenía durante el noviciacio. Pero lo que nadie sabe, lo que siempre queda oculto es lo mejor. Y lo mejor aquí es la voluntad de Lope de profesar, de ser religioso agustino, de consagrarse a Dios, de servir pronto a la Iglesia, de ser un poco lo que fue san Agustín en su tiempo y al que se había ya aflcionado.

\section{Lope en Valladolid $y$ en El Escorial}

Mientras algunos compañeros de Lope peregrinaban por La Vid y El Escorial, éste seguía anclado en Valladolid. Hasta que volvieron a encontrarse en el Real Monasterio. Fue el año de 1930. Para entonces, Fray Lope ya habia emitido sus votos solemnes, pues a los tres años justos de su profesión simple se entregó definitivamente a Dios en la vida religiosa agustiniana: 1 de octubre de 1927.

Pero Lope no había recibido aún la ordenación sacerdotal; mientras que su amigo y compañero, Dictinio, "estrenaba libertad en la parcela de los Padres". El año 1931, España conoció una primavera caliente. El día 14 de abril llegaba la Segunda República para regir los destinos de la patria de una manera ilegal, aunque blasonasen de procedimientos legitimos los interesados en implantarla. Las decantadas elecciones de dos días antes dieron una mayoría abrumadora de candidatos monárquicos; pero lo espectacular del triunfo republicano en las capitales más importantes ofreció apa- 
riencias legales y fuerza a los conjurados. Fueron unos momentos de euforia nacional que bien pronto habrían de pagar todos los buenos españoles.

La vida seminarística en el monasterio era tensa, incierta y preocupante. Aquel año se adelantaron los exámenes de fin de curso y a mediados de junio enviaron a los estudiantes filipinos con sus respectivas familias, "embutidos en un terno color ala de mosca, igual para todos, y valorado en 30 pesetas".

El P. Dictinio, fiel siempre a su privilegiada memoria, nos dice que formaban dos grupos: los sacerdotes con la carrera terminada y los que habian terminado tercer curso de Teología. Los sacerdotes fueron destinados al Perú y Colombia, excepto el P. Juventino Macho y el citado P. Dictinio Rodríguez, que fueron destinados a Roma. Los profesos, por su parte, marcharon rumbo a Filipinas, menos Manuel Ramos y Lope que debían trasladarse también a Roma.

En consonancia con los métodos de entonces, simples y expeditivos, se les intimó la orden, sin pulsar el ánimo y las preferencias de los interesados que, dóciles, modestitos y tal, aceptaron el mandato sin pestañear con equilibradas dosis de responsabilidad y de inconsciencia.

Encastillados por espacio de doce años en el convento -escribe el citado P. Dictinio-, sin ninguna salida al exterior, se les brindaba la oportunidad de asomarse a un mundo nuevo y desconocido con sus implicaciones de expectación y riesgo. Su preparación para las futuras tareas era bastante completa en lo intelectual, en lo psíquico y en lo ambiental.

Después de la primera sorpresa y del primer desconcierto, nuestros futuros maestros y formadores comenzaron a planear nuevos rumbos y dirección concreta a sus aspiraciones. Sabido es cómo el P. Juventino se decidió por la Teología, y el P. Dictinio por la Biblia. En cuanto al P. Ramos, cuya propensión al arte era evidente, se resignó a formar pareja con el P. Macho; mientras que Lope, con incipientes tendencias al Agustinianismo, pasó por dudas e indecisiones, escogiendo al fin, como mal menor, dedicarse con el P. Dictinio a la Escritura.

\section{De paso por Barcelona y el sacerdocio}

Pero antes, tendrán que estudiar la lengua de Homero con profesor particular: Lope y Ramos en Barcelona y Juventino y Dictinio en Madrid. Menguada preparación para los aspirantes al Bíblico 
con sólo unas nociones hilvanadas de griego clásico, sin idea del hebreo y sin el indispensable bagaje de lenguas modernas, si bien habian tenido cursos elementales de francés, pero estando a cero en inglés, alemán e italiano. "Eramos de verdad -escribe certero el P. Dictinio- un monumento viviente de improvisación, de optimismo y de valentía desenfrenada".

Antes de partir para la Ciudad Eterna, Lope y Ramos aprovecharian esta breve estancia en Barcelona para ordenarse de sacerdotes, cosa que efectuaron en Lérida - según tengo entendido y oído contar al propio P. Ramos y Lope- el día 8 de noviembre de aquel tristemente histórico 1931, mientras los compañeros se adelantaban en tren camino de Roma.

\section{En Roma}

El P. Lope residió, de 1931 al 1933, en el Colegio Internacional de Santa Mónica. En el primer año consiguió el bachillerato y la licenciatura en el colegio del Angélico, junto con el P. Dictinio. Necesitaban aquellos títulos para acceder a los grados del Pontificio Instituto Bíblico.

El Colegio Internacional de Santa Mónica, que la Orden Agustiniana tiene aún en Roma, se dividía entonces en varios compartimientos: los llamados padres estudiantes vivían a su aire y solamente coincidian con los demás en el coro y el comedor.

Entre los componentes del grupo existía compenetración, buen humor y verdadera camaradería. Se llevaba con mucho rigor la asistencia a los actos comunes. Eran mayoria los españoles y sudamericanos; lo cual hacia difícil aprender y practicar el italiano.

Al iniciarse el curso 1933-34, por necesidades de reforma, el $\mathbf{P}$. Lope, junto con el citado P. Dictinio y Angel Villarruel, de la provincia de España, además de los malteses Pablo Spiteri y José Borg, fue trasladado al convento de San Agustín. Un cambio que resultó beneficioso, pues, aparte el cariño con que fueron recibidos, pudieron aprender mejor el italiano y desde alli desplazarse más făcilmente al Bíblico. Por otro lado, tuvieron la oportunidad de actuar en la parroquia de San Agustín y colaborar en algunas obras de apostolado que aquella llevaba.

Tal vez, una de las cosas que más agradecieron estos estudiantes romanos al bondadoso $P$. Gabriel Monti fue el alivio de la asistencia a los actos religiosos comunes, pues le constaba de sus muchas tareas estudiantiles y de sus no pocos apuros. Aquello cayó de perlas en nuestros jóvenes religiosos, pues pudieron conseguir la Li- 
cenciatura en Sagrada Escritura y coronar el tercer curso que se consideraba como preparación para el doctorado.

Con todo tenemos que decir que, así como comprobaron en el Angélico que la cultura teológica conseguida en El Escorial era lo suficientemente amplia y firme como para afrontar con éxito las pruebas académicas que les abrian las puertas de la Licenciatura, así también pudieron comprobar que luego en el Bíblico se tornó todo más difícil y complicado para los estudiantes de lengua española. "El estudio, las clases, los trabajos que nos encomendaban -escribe el citado P. Dictinio-, los exámenes trimestrales, semestrales y finales absorbian todo el tiempo y ponían a prueba nuestras energías juveniles. Habia pocos espacios libres para paseos artísticos 0 excursiones. Reconozco de buen grado que Lope, por sus dotes personales, se defendia mejor y vivia menos ahogado que yo. Asi pudo pasar un verano en Irlanda y otro en Hipona, mientras yo estudiaba y convivía con apostólicos italianos un año en Viterbo y otro en Gubbio".

$\mathrm{Y}$ con su gracia inimitable nos recuerda algunas salidas, muy pocas, a las cercanías de Roma, en las que se divertían a lo pobre, careciendo de adecuados recursos para mayores alegrías. A Lope, por su alergia a las matemáticas, le correspondia, con cierta desproporción, soportar los gastos comunes. Aquellos buenos "camaradas" tenían bien estudiado el truco: todo era cuestión de hacer muchos números, sumas y restas, multiplicaciones y divisiones de las que resultaba, por ejemplo, que si habia que repartir un gasto de 225 liras entre cinco, a Lope le correspondían 140. Se mareaba ante el baile de los güarismos y "el inocente" pagaba sin rechistar.

$Y$ es que desde Madrid ataban corto a los estudiantes de Roma en materia de gastos. Entonces se comía mal en Roma, siendo a veces preciso recurrir - sigo casi a la letra al ingenioso P. Dictinioa algún suplemento alimenticio. Fumaban con mesura el tabaco más pobre y más popular de Roma. Andaban escasos de ropa y median mucho los dispendios en libros y material escolar. Así y todo, los gastos les parecían exagerados a los ecónomos madrileños que les endilgaron una filipica de tomo y lomo, con apremiantes exhortaciones al sacrificio, en evitación de posibles y futuros anatemas, como dilapidadores del erario de la Provincia de Filipinas.

$Y$ ahi los tenemos, en el Instituto Bíblico, un tanto acomplejados por su falta de preparación próxima ante la arriesgada empresa de conseguir los títulos académicos. Caso de salir airosos, serian los primeros que lo conseguirian de la Provincia de Filipinas. $Y$ temian por un natural sentido de la responsabilidad. Se sintieron 
también un poco como desamparados al no encontrar en la nómina de profesores un solo español. Les deslumbraban los nombres de mayor peso específico en el ambiente escolar del Centro: P. Bea, entonces rector y más tarde cardenal; P. Vaccari, Holzmeister, Semkwoski, Power, Merck, O'Rourke... Instintivamente se agruparon los hispano-parlantes, que formaban piña en los recreos y compartían alegrias, preocupaciones y penas. Eran éstos los veteranos Rey, gallego y más tarde profesor de Biblia en Compostela, y Santaeularia, después rector, canónigo y profesor en el seminario de Tarazona. Al curso del P. Lope pertenecían el P. Juan Arriola, jesuita, ondarrés, hoy en la residencia de Bilbao; Abilio del Campo, burgalés y futuro obispo de Calahorra; José Luján, murciano, actual canónigo lectoral de Lérida; Victor Hermosilla, agustino recoleto, con madera de provincial; Prisciliano Partida, seminarista mexicano, muy compenetrado con los españoles; y nuestros dos pequeños héroes Dictinio Rođríguez y Lope Cilleruelo.

Por lo que se refiere a nuestro protagonista, es de toda justicia destacar aquí los intentos y buenos deseos que ponía en el campo de la liturgia, aunque, a juzgar por los resultados, no debía ser éste su fuerte. Ya en El Escorial, los PP. Julián Zarco Cuevas y Arturo de la Fuente, jueces ladinos que admiraban la desenvoltura y graciosos despistes de Lope, se habian dado maña para pasar un rato divertido, alentando y hasta empujando las respuestas de su alumno hacia lo insólito y lo festivo:

- ¿Cuántas velas hay que encender para la exposición solemne?

Le preguntaron en un examen de Liturgia.

-Ocho velas. Contestó Lope, sin titubear.

-Fijese bien, que hemos dicho exposición solemne.

-Diez velas.

- ¿Sólo diez velas? Preguntó el P. Zarco.

- Veinte velas. Contestó el alumno Lope.

Hasta que la sonora carcajada de los jueces vino a impedir que siguiera encendiendo velas, porque igual convertía el presbiterio en una tarta de cumpleaños con lucecitas de centenario.

Pero había que aprobar el examen:

-Fray Lope, en la absolución al túmulo, ¿qué papel juega el incensario? Le preguntó ahora el P. Arturo.

- Sirve para dar vueltas al túmulo. Contestó el examinando.

-¿Cuántas?

-Cinco. 
- Nos referimos a la absolución solemne.

-Entonces, diez.

Aquí terminó el examen, seguramente que por miedo a que Lope y su incensario ganaran en revoluciones al más pintado satélite espacial. Pero, en honor a la verdad, se había ganado el aprobado a pulso.

Ahora en Roma, las Damas Catequísticas, religiosas españolas que estaban en esta ciudad, y que mantenían estrechas relaciones con el P. Santiago García, entonces procurador general, con aureola de hombre sabio y virtuoso, solían invitar en los días festivos a este religioso, que era, además, su confesor ordinario y requerian la colaboración de los estudiantes españoles en calidad de acólitos y de comparsas. Ellos acudían desinteresados y gozosos, sin que nunca resultara fallida su secreta esperanza de hacer los honores a una bandeja bien abastecida de ricos dulces caseros.

Pues bien; en una ocasión y ya al final de la misa, apareció de improviso el cardenal don Pedro Segura, que vivía en Roma, desterrado de España por el gobierno de la República. El cardenal imponía respeto no sólo por su dignidad cardenalicia, sino también por su legendario temperamento, su fama de intransigente y su aspecto penitencial y fervoroso.

Quiso que uno de aquellos estudiantes españoles le ayudara a su misa. Miró de hito en hito a cada uno de ellos, de arriba abajo, y seleccionó a Lope, no se sabe si por ser paisano suyo, o porque adivinó en su rostro cualidades litúrgicas inéditas todavía.

Lope hubiera dado cualquier cosa por eludir aquel compromiso y endosar la encomienda a uno de sus compañeros. Pero rendido a la voluntad del ilustre prelado, sólo se atrevió a musitar:

-Eminencia, que yo en punto a ceremonias ando flojillo y no actuarè con mucha seguridad.

El cardenal sonrió benévolamente y generoso, y con un golpecito en el hombro de Lope le infundió ánimo y le instó a desempeñar su oficio sin encogimientos ni complejos.

Ya antes de empezar la misa, nuestro Lope entró en funciones. No puede decirse que anduviera a la deriva, porque, la verdad, naufragó desde el primer momento. El cardenal le miraba de reojo, le sugeria con voz queda lo que tenía que hacer en cada ocasión y es posible que esperara una mejoria gradual de su acólito. Lo cierto es que Lope se sintió mareado ante la maraña de vestimentas, reverencias, saludos y ósculos, y no vamos a decir que confundiera el anillo con el solideo, pero sí que no dio una a derechas y que sintió un alivio infinito al tiempo de finalizar el santo Sacrificio. 
Su eminencia se despojó lentamente de sus vestiduras sacras recitando las oraciones de rigor y largó su diestra a Lope, el cual, arrodillado como estaba, besó reverente el anillo pastoral. Don Pedro Segura desgranó con parsimonia su gratitud y su elogio:

-Pensé -dijo- antes de empezar la misa que Vd. proclamaba su ignorancia de las rúbricas por humildad; pero me he convencido de que es cierto que no tiene Vd. ni idea; y que no ha dado una en el clavo.

\section{En la verde Erín, en Hipona y entre los hermanos malteses}

El P. Lope recuerda con verdadera nostalgia aquellos años de sus estudios en Roma. Y en ocasiones le hemos oído contar anécdotas que le ocurrieron durante las breves estancias veraniegas en Irlanda, Hipona y Malta aprovechando las vacaciones estivales.

Pero es nuevamente el $P$. Dictinio quien nos pone al corriente de todo esto. En el verano de 1933 -nos dice- el P. Lope obtuvo permiso para veranear en Irlanda con ánimo de profundizar en el conocimiento de la lengua inglesa. Fueron aquellas unas vacaciones fructiferas en lo esencial y divertidas y accidentadas en lo anecdótico. Porque ya en Francia, camino de Dunquerque, tanto Lope como sus compañeros de viaje descendieron del tren para recrearse en las delicias de la cocina francesa. Lope comió bien, saboreando los manjares con la solemnidad de un rito; pero al paladear las exquisiteces del postre, comprobó que el tren ya no estaba en la estación. Hacia varios minutos que habia proseguido su ruta, llevándose consigo la maleta y los objetos del confiado viajero.

Resultó laborioso hacerse entender por señas y a base del francés que se habla en Roa. Al fin, le colocaron en otro tren de Dunquerque donde le esperaba su bagaje. El retraso imprevisto y las gestiones conducentes a recuperar su equipaje comprometieron su llegada puntual al barco. Justamente cuando éste levaba anclas para hacerse a la mar, asomó Lope su estampa cansina, casi oculta bajo el amasijo de sus bártulos. Le esperaron entre el estupor poco amistoso de los viajeros, y Lope se asió a la barandilla del puente levadizo como quien ganaba la primera batalla al mar, con la frente muy alta, porque lo que importa es llegar.

La estancia veraniega entre los hermanos irlandeses, según sus propias referencias, fue beneficiosa para su organismo, para el inglés y para la conquista de numerosos amigos. A la hora del regreso, le sirvió de mucho el mal recuerdo de las vicisitudes del viaje de ida. Por lo que procuró atar cabos y asimilar horarios y combina- 
ciones en evitación de despistes y sorpresas. En este sentido, el viaje resultó normal; pero es posible que la concentración mental consagrada a unos problemas dejara al descubierto otras áreas que también reclamaban alguna atención por pequeña que fuera. Lo cierto es que, al llegar Lope a Roma se convenció de que era un buen cliente de las oficinas de objetos perdidos. En los numerosos hitos de su itinerario fue dejando constancia de su gratitud turistica. A la hora del recuento, faltaban de sus maletas la capucha agustiniana, el paraguas, el breviario, el servicio de afeitar, los libros comprados en Dublín y otras muchas menudencias. Menos mal que el humor no le faltaba nunca; y como apostillaba el propio Lope, aunoue hubiera resucitado la estampa del gallo de Morón, "más se perdió en Cuba".

Con tan gratos recuerdos, el P. Lope planeó para las vacaciones de 1934 una excursión a Hipona con dos finalidades bien concretas: relacionarse con el mundo árabe y su idioma, tan emparentado con el hebreo, y tan útil para desentrañar no pocos misterios y peculiaridades fllológicas y estructurales de la lengua santa. Le atraía, asimismo, una llamada apremiante: conocer "in situ" el escenario geográfico de Hipona y sus alrededores donde nació, escribió, predicó y se fraguó la personalidad de Agustín, africano, escritor, obispo y santo.

En Hipona pasó dos meses estivales entregado con denuedo a su doble tarea, fraternalmente acogido y asesorado por el $\mathrm{P}$. Merlin, francés, y el P. Mizzi, maltés.

Al regresar a Roma le pareció obligado hacer escala en la isla de Malta, de tan gloriosos y a la vez descalabrados recuerdos del viejo imperio español, accediendo a los deseos de los malteses P. Spiteri y Borg, compañeros de fatigas en San Agustín. Le agasajaron con gran cordialidad. Pensemos que, por aquel tiempo, eran muy pocos los titulados en Sagrada Escritura; por lo que el P. Lope, que acababa de estrenar Licenciatura, recibió singulares honores y fue presentado a las gentes como una eminencia agustiniana en ciernes.

Al tiempo de planificar su regreso a la Ciudad Eterna, estimó oportuno adquirir algunas especies de tabaco exótico, con el ánimo de agasajar a los amigos. Conocía los riesgos de la inspección aduanera; pero ingenioso como siempre, dio con la solución: sendas cuerdas en las pantorrillas formaron unas bolsas pantaloneras, y en ellas pudo alojar el tabaco. Pero no contaba con un imprevisto. Cuando Lope celebraba misa, al hacer la genuflexión, cedió una de las cuerdas y el presbiterio apareció sembrado de cajetillas. 
Durante su estancia en Roma, Lope no se olvidó de los suyos y les envió una Bendición Apostólica del papa Pío XI, y un cuadro pintado por él mismo con destino a un primo suyo que tenía vocación de religioso y esperaba ir con Lope, pero su padre se opuso en redondo y luego murió durante el servicio militar en Logroño.

Tampoco la familia se olvidaba del hijo bueno y ya famoso. Estando todavía Lope en la Ciudad Eterna, el señor cura párroco de Roa, el ejemplar y venerable don Bonifacio, hizo un viaje hasta Roma, ilusión y sueño de muchos eclesiásticos, para ver al papa Pío XI, visitar las catacumbas y admirar el arte de Miguel Angel y de Rafael por el Vaticano. Tuvo tiempo de acercarse al Colegio Internacional de Santa Mónica y dar un abrazo a su ilustre paisano y antiguo feligrés. Le llevaba, entre otras cosas, un paquete de almendras que le debieron saber a gloria, y mejor a sus compañeros de estudio, a juzgar por lo que el propio Lope va a decir en una carta que escriba de agradecimiento a sus padres, y en la que cuenta cómo aquéllos le habían roto los bolsos del hábito y del pantalón para quitarle las famosas y dulces garrapiñadas de Roa.

Don Boni nunca olvidaría aquel viaje, ni al buen "cicerone" que tuvo durante su estancia en Roma, pues Lope, el estudioso de Lope, haciendo seguramente de tripas corazón -pero ahí está la virtud-, encantado y jovial, le acompañó por la ciudad de los papas, por la Roma imperial y por las primeras mansiones de los perseguidos cristianos. Tan redondo le salió el viaje que, como yo se 10 he oído contar al venerable sacerdote, deseando celebrar misa en las catacumbas, sin saberlo Lope, le preparó justamente el altar de Santa Petronila, nombre que llevaba su madre, y a la que tenía, por este motivo, especial devoción.

\section{El destape oratorio de Neguri}

En el mes de agosto de 1935 el P. Lope estaba de regreso de Roma en Valladolid. Se encontraba también el P. Dictinio, aunque hubieran llegado por distinto camino. El 24 de aquel mes sería consagrado obispo de Teruel el P. Anselmo Polanco en la iglesia casi recién estrenada y en la que tanto esfuerzo habia puesto siendo rector de aquella comunidad.

El P. Lope pudo hablar en aquella ocasión con el que poco tiempo después iba a ser figura heroica en España. Durante la conversación, se le ocurrió sacar un cigarro y ponerse a fumar delante del que, siendo Provincial de Filipinas, había dicho a los estudiantes romanos que podían fumar en Roma, pero que en cuanto llegaran a 
España, ni un solo cigarro hasta tanto que se lo permitieran las sagradas Constituciones. El P. Polanco que tenía buena memoria y que estimaba mucho a Lope desde los dias en que tuvo que concederle y negarle permisos y dispensas cuando hacía el oficio de "rector de colegiales", le recordó el mandato de Roma. Lope, con su vivacidad y gracia característica, le contestó:

- Somos exentos, excelencia.

Finalizada la ceremonia, el P. Provincial, entonces Joaquín Geijo, mandó rápidamente a los dos - a Dictinio y a Lope-camino de Neguri para que suplieran en la iglesia a algunos conventuales de aquella residencia y se ensayaran, al mismo tiempo, en la oratoria sagrada.

La anécdota, una vez más, la cuenta el P. Dictinio, con el remoquete de "el destape oratorio de Neguri". Cuando esperaban ir de vacaciones a sus respectivos pueblos, el P. Geijo les envió como joven refuerzo veraniego de aquella comunidad. Al llegar, los dos quedaron impresionados por las arrugas y el aspecto severo del P. José Marcos y que luego florecerian en un gran clima de comprensión y de amistad. En Neguri - dice el P. Dictinio- se entrenaron en el asalto al púlpito del Carmen, más por obligación que por devoción. Por privilegio de edad le tocó al P. Dictinio abrir el fuego y estrenar oratoria en la misa más concurrida. El dice que salió adelante como pudo; pero todos sabemos de la labor suya en este campo del apostolado y de lo bien que se le ha dado siempre el púlpito. Lope solicitó enseguida informes al compañero sobre ambiente y concurrencia; y aquel procuró desvanecer sus preocupaciones e infundirle aliento. A la hora de la verdad, salvó Lope la sacristía y, como el soldado que va a librar trascendental batalla, miró de reojo la masa humana que abarrotaba el templo y escaló con decisión los peldaños del púlpito. Entre curioso y asombrado, bajo el prisma del estupor y del miedo, se le antojó que le espiaba una muchedumbre curiosa y despiadada. Se le evaporaron las ideas, se atropelló su ritmo cardíaco, no se fió de la ayuda del Espíritu Santo y con ademán pausado y unción apostólica se protegió con la señal de la cruz y emprendió la retirada, escaleras abajo, presuroso y altivo, tras su elocuente predicación silenciosa.

Sin pretenderlo, había conquistado un púlpito y una fama. Por eso, al incorporarse al seminario vallisoletano en el mes de septiembre, los superiores le nombraron profesor de Oratoria Sagrada. 
Lope, soldado de España

Al tiempo de escribir el P. Amador del Fueyo su libro sobre "Los Agustinos en la Revolución y 'en la Cruzada", pidió informes a cuantos religiosos de la Orden habian tomado parte en la contienda. Lope fue uno de los que, de verdad, estuvo en la guerra. Cuando el citado P. Fueyo le escribió pidiéndole informes sobre el particular, nuestro biografiado le contestó con una "relación picuda y sucinta", que en ningún modo daba la menor idea sobre las actividades y correrias y episodios de Lope durante la guerra.

Cuando estalló el llamado Movimiento Nacional, Lope estaba cumpliendo el servicio militar en Zaragoza, tomando parte en el alzamiento con las compañias de zapadores, que se adueñaron pronto de los servicios públicos. Poco después, marchó de "dinamitero" -como él dice- en una expedición que se dirigía a Fuentes y Belchite para contener el avance de los rojos que se corrian por alli, y siendo uno de los que participaron en la voladura del puente del último pueblo citado. Por el mes de agosto realizará esta misma operación por Cariñena y la patria chica del pintor Goya, Fuendetodos, regresancio sin novedad a Zaragoza, después de volar varios puentes y "pasar unos días de campo".

Erá Lope un soldado y nada más. Hasta el punto de que, en los primeros dias, los jefes del Regimiento de Zapadores ignoraban que era sacerdote. Más tarde se enteraron tal vez porçue se "chivó" uno cualquiera de los jóvenes agustinos, incorporados a filas, y que le acompañaban en aquellas expediciones.

Habiéndose formado una compañía para Huesca, a Lope le tocó ir de soldado-capellán, permaneciendo mucho tiempo en primera línea y pasando en ocasiones verdaderos apuros, con peligro de su vida. Por la noche, cavaba trincheras; por la mañana, hacía el oficio de cartero y salía al hospital donde celebraba la misa. Las hijas de la caridad de Santa Ana hacían honor a su nombre agasajándole con un buen desayuno y limpiándole la guerrera y el pantalón que llevaba lleno de barro.

A medida que avanzaba el tiempo, se fue ganando la amistad de sus superiores, que le recordarán siempre; lo mismo que Lope a ellos. El capitán le dispensó de "picar", siguiendo de cartero y diciendo misa para la tropa de Huesca y Alerre, donde quedaba una sección de zapadores.

Es admirable comprobar cómo este hombre, que de verdad se rompió el pecho durante la guerra, ha sabido luego enjuiciarla con un equilibrio y ponderación que falta a otros muchos que jamás es- 
tuvieron en el frente de batalla. El P. Lope es un hombre que vivió de cerca los acontecimientos, y es tan inteligente como para no dejarse engañar por los viejos slogans, ni por radicalismos patrioteros. Estaba convencido de que cumplía con un deber y que iba a morir en Huesca. $Y$ cuando su cuñado Antón vaya a visitarlo, después de cruzar un efusivo abrazo con él, le dijo: "vete a casa y cuida de la familia, Antón; que a Julio y a mí nos matarán". Profecia que en parte se cumplió, pues al hermano menor, a Julio, una bala perdida le mató justamente el día en que el general Franco daba el último parte de guerra, habiendo realizado toda la campaña sin recibir ni la más pequeña herida. El destino; dirá alguno. Cosas de la guerra.

Lo mejor que podemos decir en alabanza a Lope y dentro del contexto que nos ocupa es transcribir a la letra las palabras que él mismo envió al citado P. Fueyo: "Juzgo imposible narrar nuestras peripecias bélicas, que fueron las de todos los soldados, ni más ni menos. A nuestro favor tenemos el no haber pedido nunca enchufes y haber renegado lo menos posible". Lope pudo haberse quedado en Jaca $y$ en Ayerbe, donde estaba la plana mayor y la retaguardia. Pero prefirió residir en Huesca, donde rondaba a todas las horas la muerte y los soldados necesitaban de un capellán. Acompañó siempre a la sección que más peligraba, y, fiel a su compañía, nunca la abandonó en cuantas ocasiones entró en fuego, siendo memorables las jornadas de Lierta y la de "Las Mártires", en cuya loma cayeron gloriosamente casi todos los de su compañia, quedando solamente vein iocho soldados, un sargento y nuestro capellán, al amparo de unas casas, pero firmes en su puesto y haciendo recular a unos mil quinientos guardias de asalto enemigos. Así era Lope. $Y$ estas facetas de su vida deben contar a la hora de valorar su paso por la tierra.

Cuando se inicie la ofensiva contra Cataluña y la guerra esté prácticamente liquidada, Lope será nombrado capellán del servicio de automovilismo, donde sirvió por espacio de tres o cuatro meses hasta ser definitivamente licenciado.

\section{Profesor de Zaragoza}

Antes de que comenzara la guerra y durante el curso de 193536, el P. Lope se inició en la docencia en el colegio de Zaragoza, recientemente inaugurado. Enseñaba Biblia y "cuanto le echaran"; todo un manojo de disciplinas. Era el estilo de entonces que forzaba a los profesores a diversificarnos y a calentar el sillón frailuno; sin 
posibilidad de profundizar en nada, en expresión literal del P. Dictinio.

Los profesores de entonces formaban una piña, no sólo por la convivencia física, sino y sobre todo por un claro sentido de confraternidad y amistad. Tiempos aquellos, en tantos aspectos admirables. Era una vida ingenua, sencilla, de reducidos horizontes, de alegría algo infantil, con bromas de buen estilo, con mutua ayuda y compenetración amistosa. Siempre juntos en los recreos, en los paseos por la huerta, en las salidas por los aledaños de la ciudad.

$\mathrm{Y}$ de nuevo la anécdota ilustrativa de la vida de Lope. Nuestro biografiado, junto con el inseparable P. Dictinio, celebraban los días festivos una misa en las Teresianas. Si pronunciaban homilia, les daban una peseta a mayores. "A Lope estuvieron a punto de suprimirle el extra por haberse comido el credo en la misa de la Inmaculada".

\section{En Valladolid, impulsor de una cultura y maestro de la juventud}

La vida del P. Lope se identifica con la de sus escritos, su docencia y el mecenazgo que ejerció entre muchos de sus discípulos, a los que animó, corrigió y orientó en sus aficiones eclesiásticas, culturales y religiosas. Quizá se haya pasado por alto esta labor y no se haya dado importancia a estos hechos. Pero cuando pasen los años y se haga la verdadera historia de la Provincia de Filipinas por los años cincuenta, entonces se verá mejor lo que fue y significó entre la juventud de aquellos días el $P$. Lope Cilleruelo. Tendríamos que recordar aqui el nacimiento de la revista "Casiciaco" en el año 1947. Nacioa en una de las nobilísimas inspiraciones de su inteligencia, calentada al calor de su entusiasmo, por él regada cuando era tímido brote nada más, hasta convertirla en frondoso árbol, al $\mathbf{P}$. Lope debió cuanto fue. El trazó a los jóvenes de entonces el plan y el criterio a seguir. De él recibíamos aliento y consejo, dejando un margen abierto a nuestras aficiones particulares.

La revista "Apostolado" también le debe mucho, aunque figure por muy poco tiempo como director de la misma y ya viniera publicándose años atrás. Pero él la dio nueva orientación y los continuadores le siguieron por aquel nuevo derrotero, aparte su colaboración continuada y siempre interesante y amena.

Si se nos permitiera la expresión, diríamos que Lope fue un verdadero revolucionario, un innovador y reformador de lo que entonces recibía el nombre de "Coristado" de Valladolid. Comenzó por la citada revista "Casiciaco", un sueño que quizá viniera teniendo des- 
de los días en que tomó contacto con los jóvenes profesos en el colegio de Zaragoza, donde en tono menor y más en privado se estaban haciendo ensayos de este tenor.

Pero lo fue luego, igualmente, con el nuevo método de vida religiosa que fue introduciendo contra viento y marea en Valladolid: sus inolvidables clases espirituales; su amor y entusiasta estudio por San Agustín y todo lo auténticamente agustiniano; su nueva mentalidad en la vida expansiva de los seminaristas; la lucha por conseguir un modesto campo de fútbol para sus muchachos, siendo él el primero en bajar al campo a las horas de recreo y obligarnos a todos a jugar, con o sin pantalón de deporte; su modo de pensar en cuanto a silencios y recreos, a la misma vida comunitaria, a la música, liturgia, canto del gregoriano y estudio serio de todas estas cosas.

El P. Lope se ha hecho famoso por algunos "slogans" de su cuño o que, siendo de otros, los ha sabido aplicar para su vida y para la de cuantos han pedido un consejo suyo, que han sido muchos. "A nadar se aprende nadando"; nos solía decir. Claro, que hay estilos; pero él siempre tuvo como norma lanzar al río al individuo y dejarle que nadara... Luego, echarle una mano, cuando se viera en dificultad. Para él, lo importante era nadar.

\section{De paso por Madrid}

Recién terminada la guerra civil española, el $P$. Lope tuvo que hacer un viaje a Madrid, en un tren que llegó con varias horas de retraso; lo que ocasionó a nuestro biografiado dar pruebas, una vez más, del despiste que le ha acompañado toda la vida. La anécdota nos la cuenta de nuevo el P. Dictinio. Al llegar a la Estación del Norte, le pareció correcto avisar a la residencia de Goya, pues era ya al filo de la media noche. Pidió una Guia telefónica de antes de la guerra y marcó un número. Esperó. Una voz somnolienta y ronca respondió a su llamada y le lanzó una sarta de insultos:

-Aquí no hay frailes ni monjas. Váyase Ud. a paseo y no me turbe el sueño.

A estas palabras tan cordiales, Lope pensó que habia marcado mal la cifra correspondiente a los PP. Agustinos. Y repitió la llamada.

La reacción del pobre hombre se tornó más airada y violenta. Conocemos con pelos y señales a dónde mandó a Lope y los improperios que dedicó al sufrido gremio de los frailes y las monjas...

Años adelante - de 1953 a 1954 - volverá Lope a Madrid, esta 
vez como definidor de provincia, si bien, como dice él siempre. "in defectu" y de suplente. Efectivamente, fue el año 1955 cuando hubo necesidad de acudir a esta norma señalada por las Constituciones. Pero Lope seguiria viviendo en Valladolid, aunque, por esto mismo, tuviera que realizar bastantes viajes a la capital de España, y pasar en ella algunas temporadas.

A decir verdad, no le sentaron mal los aires del Guadarrama, y los paseos por "el Rastro" y su participación en las labores de la iglesia, aunque en esto será mejor escuchar, nuevamente, al compañero y amigo.

Por riguroso orden semanal -dice el P. Dictinio-, un padre quedaba en guardia por la tarde. Cuando le correspondía el turno a Lope, solia quedarse él en la reserva por si no llegaba a tiempo para el rosario y acto eucaristico vespertino. Lope, según su propia confesión, tropezaba con dos serias dificultades: unas veces se olvidaba de que le correspondía actuar y otras de consultar su reloj, que tampóco era un prodigio de precisión. $\mathrm{Y}$ de este modo, o no llegaba, o lo hacía con retraso.

Pero ved por dónde un buen día regresó de la calle a todo correr, recorrió la iglesia sin advertir que ya estaba expuesto el Stmo:, se revistió en un santiamén y se disponía ya a exponer cuando el Hermano Alejo le paró los pies. Lope aceptó complacido la observación, y echándose la capa pluvial sobre los hombros se encaramó al púlpito con la intención de rezar el santo rosario. Menos mal que no habia gente en el templo y el citado hermano sacristán pudo intimarle en tono jovial que descendiera, ya que faltaba casi media hora para iniciar la función.

\section{El Consiliario de Acción Católica}

Residiendo en Zaragoza comenzó Lope a distinguirse como entusiasta propagandista de la Acción Católica; tarea que continuó más tarde y más en activo en Valladolid. Todavía se le recuerda entre los veteranos que quedan de entonces.

En muchas ocasiones han salido a relucir aquellas jornadas de los años cincuenta y cuando la A.C. estaba en todo su apogeo y era de verdad "la niña mimada de la Iglesia". El P. Lope, siempre genial, hasta por sus involuntarios descuidos y desplantes ocasionales, era un poco el centro de afanes y trabajos comunes y el organizador de actividades apostólicas. Hay una anécdota que se recuerda con regocijo de todos. Eran los días en que nuestro biografiado gozaba del favor de un grupo de jóvenes universitarios a los que asesoraba 
y dirigia con evidente competencia y con mucho acierto. Varios de aquellos entusiastas muchachos ocupan hoy puestos relevantes en las universidades y en la administración pública. Lo más difícil era mantener la tensión apostólica entre ellos, ya que por presión de los estudios, o por atención a las novias, no asistian siempre a la hora convenida ni al lugar señalado.

En cierta ocasión resultaron tan llamativas y descorazonadoras las ausencias, que Lope montó en cólera y amenazó con liquidar las reuniones si no se demostraba más interés y asiduidad en la asistencia. Aquello fue como un "ultimatum" para el jueves siguiente.

Los pocos presentes avisaron a sus compañeros, ausentes del coloquio, y surgió una especie de plebiscito tácito que desembocó en asistencia masiva y expectante. Habia buena voluntad, contrición por lo pasado y ganas de trabajar en el futuro. Lo bueno del caso fue que solamente hubo una ausencia: la del $P$. Lope. Este no había caido en la cuenta de que era jueves y de que aquella noche le esperaban todos los miembros juveniles de Acción Católica, incluso los que casi nunca solían acudir a lo que entonces se llamaba "círculos".

\section{El religioso humano y comprensivo}

Recogido en su habitación, consagrado al arduo e ingrato ejercicio de la enseñanza y al cumplimiento de los deberes que le imponía la vida religiosa, el $\mathrm{P}$. Lope, su clara y vasta inteligencia, brillaba más entre sus alumnos y hermanos de corporación, salvo los pocos amigos y los que tomaban contacto con su palabra en las obras de apostolado arriba referidas.

Como religioso, quizás, no haya sido bien comprendido el P. Lope Cilleruelo. Con sus despistes y desaliño en el vestir, con su desarraigo de las cosas, ha ocultado siempre una fina sensibilidad y un sentimiento claro del deber.

Como profesor, cuantos han pasado por sus aulas jamás olvidarán el atractivo de su palabra y amenidad de expresión con que sabe revestir los temas más complicados. y serios de espiritualidad o Biblia.

En cuanto a su trato, el P. Lope es una paradoja: trata de huir de las personas, pero donde él está abunda el sano humor, la gracia, la chispa ingeniosa y la alegria que, a las veces, rompe en hilaridad espontánea e inevitable.

Generoso alentador de todo lo bueno, de todo lo bello, almä no- 
ble y sincera, este hombre que ha sido formador de varias generaciones, es recordado con gratitud por muchos.

El ve como la cosa más natural del mundo las excepcionales dotes con que el Señor le ha enriquecido. No las da importancia, y solamente las valora cuando tiene que ponerlas en servicio de los demás, sin pasar nunca la factura por ello.

El P. Lope es uno de los hombres más humanos y comprensivos con que me he encontrado en mi vida. Su conversación amena, ajena a toda etiqueta aun en los casos más solemnes; el tino con que, al través de ella, sabía conciliar la sinceridad con lo que piden, a veces, las circunstancias y exigencias sociales, le captaban sin remedio las simpatías de todos.

Cuando en el mes de octubre de 1976 tuvo que ser intervenido de una delicada operación, en los círculos de amigos, de dentro y de fuera de la comunidad, se comentaba que si el P. Lope nos llegara a faltar, se nos iria el buen humor, la gracia y la sana alegría de la comunioad y de las reuniones a las que asiste por razones de cursillos de cristiandad y de otras obras de apostolado en las que todavía colabora, aunque no con el entusiasmo y asiduidad de hace algunos años. Es inteligente el $P$. Lope y sabe muy bien que todo esto contribuye a una convivencia fraternal y que esto hay que llamarlo, porque lo es, verdadera caridad.

\section{Un talento de excepción}

Algunos se han preguntado qué hubiera sido el $P$. Lope de haber profesado en la Compañía de Jesús, por ejemplo. Yo creo que hubiera sido todo - un especialista, quizá- menos el P. Lope. Es un autodidacta en toda la extensión de la palabra. Es posible que no encontrara en los años de su juventud - como nos lo ha dado a entender el P. Dictinio- un guía y un mentor apropiado. $Y$ es posible también que la guerra del 36 dejara profunda huella en su vida y en su quehacer, un tanto legionario y aventurero. Los hombres de su generación fueron todos ellos marcados por ese sello indeleble; como lo fuimos la siguiente por los años de la postguerra.

El P. Lope, autodidacta, fue acumulando a lo largo de su carrera gran riqueza de variados conocimientos; pero fue a costa de no especializarse en ninguno, aunque su carrera sea de teología y obtuviera en Roma un título académico en Sagrada Escritura. En Roma estudió Biblia; pero lo mismo pudo haber estudiado dogma o moral.

Yo creo que el P. Lope es un humanista al estilo de Fray Luis 
de León, de Vives, o de Juan de Valdés. O, quizá, sea una amalgama de los tres. Quizá, de haberse dedicado plenamente al estudio de San Agustín, sería hoy uno de los mejores de Europa en este campo, y el mayor agustinólogo dentro de la Orden. Pero estoy convencido de que, de haberse dedicado a la literatura y concretamente a la novela, hubiera sido un gran novelista y con una profundidad temática que la mayor parte de ellos no tienen, porque no tienen el saber filosófico y teológico de Lope, aunque puedan tener idéntica inventiva.

Amante de las buenas letras, poeta nato, artista y escritor de ágil estilo; dotado de una facultad de asimilación verdaderamente portentosa, ha sabido improvisar con una facilidad que, tal vez, le haya perjudicado precisamente por ser tan favorecido.

Y finalmente, su humildad. Una de las cosas que más he admirado siempre en el $P$. Lope es su absoluta carencia de empaque y de entonos, de infulas magisteriales. Con humildad, tanto más hermosa, cuanto más limpia de todo egoísmo y gazmoñería; antes, al contrario, alegre y espontánea, como de quien la lleva connatural en el alma y en el ser entero, nunca se ha dado aires de maestro, aunque lo haya sido; ni de profesor, aunque siga siéndolo todavía y quiera Dios que por muchos años para gloria de la Iglesia y de la Orden Agustiniana.

TEÓfILO APARICIO

Estudio Teológico Agustiniano Valladolid 